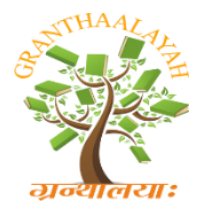

\author{
INTERNATIONAL JOURNAL OF RESEARCH \\ GRANTHAALAYAH \\ A knowledge Repository
}

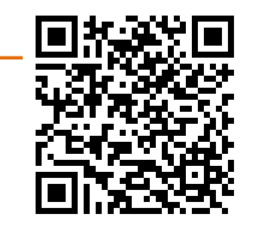

Science

\title{
EFFECT OF UNILATERAL NEPHRECTOMY ON KIDNEY FUNCTION IN FERAL DOMESTIC CATS (Felis catus)
}

\author{
Dr. Dionesio A. Estopa *1 \\ ${ }^{* 1}$ Associate Professor \& Director, Veterinary Teaching Hospital, College of Veterinary Medicine \\ University of Eastern Philippines
}

\begin{abstract}
This experimental study was conducted to determine the effect of unilateral nephrectomy on kidney function through hematological and urological values after surgery using feral domestic cats. Four (4) apparently healthy stray male cats were caught and used as experimental animals in this study. The animals were grouped into two (2) with two cats in each group. Grouping of the animals was based according to age, the 1st group - ages one year and above ( $>1$ year) and the 2nd group - ages one year and below ( $<1$ year). A split plot randomized complete block design was used in the experiment. The result shows that rectal temperature and packed cell volume have been affected on both age group of cats and other urological values like the presence of urobilinogen, protein, leukocytes, erythrocytes and crystals were elevated twenty four hours after surgery. A significant increase on the level of creatinine and blood urea nitrogen has been noted from the 3rd and 15th post - operative day. However, no significant difference was noted between experimental animals and the two age groups, all of which have similar result. The findings of the study revealed that the remaining kidney could not completely compensate the function of the other kidney up to the 15 th post - operative day, it may take longer than fifteen days. Hence, proper supportive treatment, post-operative care \& management of animals subjected to unilateral nephrectomy is a must and should continue beyond fifteen days.
\end{abstract}

Keywords: Unilateral Nephrectomy; Feral Domestic Cats; Kidney Function.

Cite This Article: Dr. Dionesio A. Estopa. (2019). "EFFECT OF UNILATERAL NEPHRECTOMY ON KIDNEY FUNCTION IN FERAL DOMESTIC CATS (Felis catus)." International Journal of Research - Granthaalayah, 7(2), 101-107. https://doi.org/10.29121/granthaalayah.v7.i2.2019.1012.

\section{Introduction}

The kidneys of cats (Felis catus or Felis silvestris catus, previously Felis domesticus) are beanshaped and yellowish-brown in color that sit at the back of the lower abdominal cavity on either side of the spinal cord, predominantly in the lumbar region. Removal of the kidney (nephrectomy) is often considered because of severe damage due to trauma, neoplasia, infection, or obstruction of the ureter. These disorders are commonly treated by unilateral nephrectomy (Birchard and 
Sherding, 2000). BUN (Blood Urea Nitrogen) and creatinine are both indicative of urinary and kidney function. Creatinine is an overall indicator of declining kidney function. Almost half of the total NPN (nonprotein nitrogenous) component of blood is urea nitrogen. Normally, all plasma creatinine passes through the glomerular membrane and none are reabsorbed. Any condition which impairs glomerular filtration will result in increased serum creatinine levels (Sirois, 1995). It is the purpose of this study to have an appreciation on the function of the kidneys after the surgical operation and to distinguish what particular components will be affected after the procedure. In addition, this will serve as a guide in the pre and post operative evaluation of surgical patient subjected to unilateral nephrectomy and to anticipate repercussion in the post-operative care and management on what particular components will be affected after the procedure.

\section{Materials and Methods}

\section{The Experimental Animals}

Four (4) apparently healthy feral cats were used in this study. Experimental animals in the $1^{\text {st }}$ group composed of two males, with ages one year and above ( $>1$ year), and $2^{\text {nd }}$ group with another two males, ages one year and below ( $<1$ year).

\subsection{Methods}

\section{Pre-operative Procedure}

Pre-operative evaluation of all experimental animals was conducted 24 hours before the scheduled surgical operation. Only healthy cats with normal PRT (Heart/pulse rate, Respiratory rate and Temperature), Urinalysis, Clotting and Bleeding time, PCV (Packed Cell Volume) and with good body condition was used in the study. The site of the blood collection was on the cephalic vein of either forelimb, and intravenous catheter for fluid maintenance was placed.

\section{Kidney Function Test}

By proper restraining the area was clipped and aseptically prepared the skin over the cephalic vein. Using a $5 \mathrm{ml}$ syringe and 21 gauge needle a $2 \mathrm{ml}$ blood was withdrawn. The blood from the syringe was being transferred to the redtop test tube through a slanting angle. Blood sample was left to stand for 20 to 30 minutes in order for the serum to separate from the blood and placed into a container with dry ice. Redtop test tubes were labeled accordingly and were transported to the diagnostic laboratory.

\section{Surgical Procedure}

The flank approach was used. The kidney of either side was exposed by packing abdominal viscera behind the mesentery of the descending colon and the viscera. The kidney was freed from its sub lumbar attachment by a combination of sharp dissection with scissors and blunt dissection with a finger or gauze sponge. Minor hemorrhage was encountered from hypertrophied capsular vessels, but it soon stopped or was easily controlled by ligation. The arterial supply was isolated close to the aorta proximal to any interlobar branches. The ureter was isolated by dissection as far as the bladder. Mass ligation of the renal artery and vein were convenient but was not recommended because of the possibility of displacement of the ligature or the development of an arteriovenous fistula. Cardiovascular silk (2-0 to 1) was an excellent material for ligating blood vessels. Ligatures can be placed and tied directly around the blood vessels or tied around previously placed forceps. 
The ureter was ligated and divided close to the bladder to prevent retention of urine in the ureteral remnant, which could promote infection, and to decrease the risk of spread of a renal tumor. The patient was not uremic or in shock and no special care was required after unilateral nephrectomy. The abdominal wall, subcutaneous tissues, located by abdominal palpation and manually immobilized. A syringe ( 5 to $20 \mathrm{ml}$.) with a needle attached ( 20 to 24 gauge, 1 1 $1 / 2$ to inches long) was inserted through the abdominal wall and into the bladder. The needle was inserted a few centimeters cranial to the neck of the bladder instead of into the vertex. The needle was introduced into the bladder lumen at an angle, as this permits rapid sealing of the bladder wall wound when the needle was withdrawn. Gentle suction was done to remove as much urine as possible (Coles, 1980).

\section{Urine examination (Physical, Chemical and Microscopic)}

One milliliter urine sample was poured into a clean test tube and physical appearance was noted. The color and appearance or transparency of the urine was observed then recorded it on the work sheet. The urine was centrifuged at a medium speed for 5 minutes and prepared for chemical examination using urine stip. The test tube was held slanting in order for the urine to penetrate to the dip strip and making it sure not to touch the area impregnated with the reagent. The chemical reactions were obtained by comparing the color of the standard provided in the bottle and then the results were recorded.

The supernatant urine was discarded by inverting the tube quickly without shaking it and the sediments will remain at the bottom of the tube. Then a drop of sediment was put into a clean glass slide and covered it with cover slip. Under high power objective (40x) the slide was examined for red and white blood cells. Casts, crystals and bacteria were examined under low power objective (10x). The results were recorder on a worksheet.

\subsection{Analysis and Interpretation of Data}

The experiment was laid out in a split plot randomized complete block design. The main plots are the sex and age groups while the days after unilateral nephrectomy are the sub - plots.

\section{Results and Discussion}

Table 1 shows the resting heart rate, resting respiratory rate and rectal temperature before and 24 hours after nephrectomy in cats. As shown in the table, the post - operative values slightly vary from the pre operative data particularly the heart rate and the respiratory rate but they are within the normal range. However, body temperature in all experimental animals increased 24 hours after unilateral nephrectomy. Slight fever was observed from the three (3) cats under study. Increased in body temperature is considered patho - physiological reaction of the body from injury, particularly after surgery. Fever after surgery is one of the most common complications that patients face. In fact, over half of all surgery patients will have a higher than normal temperature in the days following their procedure. In fact, for some low-grade fevers, no treatment is necessary (Hines, 2012). 
Table 1: The Average Resting heart rate (beat per minute), resting respiratory rate (beat per minute), rectal temperature (degrees Celcius) before and 24 hours after nephrectomy.

\begin{tabular}{|l|l|c|c|}
\hline & Reference Values & Pre-operative Period & 24 hours Post-operative Period \\
\hline Heart Rate & $\mathbf{1 2 0 - 1 4 0}$ & $\mathbf{1 3 4}$ & $\mathbf{1 3 0 . 5}$ \\
Resp. Rate & $\mathbf{1 6 - 4 0}$ & $\mathbf{3 3 . 5}$ & $\mathbf{3 1 . 2 5}$ \\
Rectal Temp & $\mathbf{3 8 . 1 - 3 9 . 2}$ & $\mathbf{3 8 . 7}$ & $\mathbf{4 0 . 1}$ \\
\hline
\end{tabular}

Clotting time before and 24 hours after nephrectomy in cats is presented in Table 2 . The post operative clotting time shows to be the same with the pre - operative values. It could be inferred that unilateral nephrectomy in cats does not affect the clotting time.

Adequate blood clotting is very important if you are about to have a surgical procedure. Modern surgical techniques have resulted in an overall decrease in significant bleeding, but there has been an increase in blood clotting abnormalities that develop after exposure to an agent or compound (Fleck and Bräunlich, 1984).

Table 2: Average clotting time before and 24 hours after nephrectomy

\begin{tabular}{|c|c|c|}
\hline Reference Values & Pre-operative Period & 24 hours Post-operative Period \\
\hline 2 - 5 minutes & 3.33 minutes & 3.06 minutes \\
\hline
\end{tabular}

Presented in Table 3 is the bleeding time before and 24 hours after nephrectomy in cats where it showed all normal values on the pre - operative period and post - operative period. Bleeding time remains the same and was not affected after nephrectomy. The bleeding time is a widely used and popular test to explore primary homeostasis. The most common use of the bleeding time is as preoperative screening of potentially dangerous platelet disorders. Surgery entails a major challenge to homeostasis, which may be fatal in case of haemostatic defects (De Caterina et al., 2013).

Table 3: Average bleeding time before and 24 hours after nephrectomy

\begin{tabular}{|c|c|c|}
\hline Reference Values & Pre-operative Period & 24 hours Post-operative Period \\
\hline 2 - 4 minutes & 2.8 minutes & 2.6 minutes \\
\hline
\end{tabular}

Presented in Table 4 is the Pack Cell Volume (PCV) before and 24 hours after nephrectomy. As shown in the table, the Pack Cell Volume of all experimental animals were all affected after unilateral nephrectomy and goes down below the normal range 24 hours post - surgery. Several hours after hemorrhage, plasma volume increases due to a shift of interstitial fluid into the vascular space. Patient responds to a low hematocrit depends on whether the blood loss is acute or chronic. However, a patient with chronically low hemoglobin, such as a patient on renal dialysis, may tolerate abnormally low hemoglobin (Coles, 1980).

Table 4: Pack Cell Volume before and 24 hours after nephrectomy

\begin{tabular}{|c|c|c|}
\hline Reference Values & Pre-operative Period & 24 hours Post-operative Period \\
\hline $30-45 \%$ & $35 \%$ & $26.25 \%$ \\
\hline
\end{tabular}

All experimental animals showed normal values on their urine physical examination both on the pre and post operative days. Chemical examination however, reveals a notable change on the post 
- operative day regardless of age. Appearance of leukocytes, urobilinogen, protein and erythrocyte on the post - operative period in all experimental animals were observed. And on the same table it also shows the microscopic examination results wherein number of red blood cells and white blood cells per high power field were elevated 24 hours post - surgery in all experimental animals. Although appearance of casts and crystals were normal but no bacteria were observed both on the pre and 24 hours post - surgery. Increased red cells in urine may be due to hemorrhage, inflammation, necrosis, trauma, or neoplasia somewhere along the urinary tract (Chew, 1998). An abundance of white blood cells seen under microscopic examination may signal some type of inflammation of the lower urinary tract, bladder or kidneys (Fieldorczyk, 2011). A detectable level of urobilinogen in the urine indicates that the bile duct is open and that bile is able to flow out of the gall bladder into the intestines. Mild proteinuria in a concentrated urine sample may not be a cause for concern (Ruotsalo \& Tant, 2011). Common crystals seen even in healthy patients include calcium oxalate, triple phosphate crystals and amorphous phosphates (Khan, 2010).

The creatinine level in cats before and after unilateral nephrectomy is presented in Table 5. It is shown that all experimental animals have the same reaction after the removal of one kidney. Creatinine level increases after surgery but the increase is still on a tolerable level up to the $3^{\text {rd }}$ post - operative day. However for animal number 3 and 4 (below 1 year) the creatinine level continue to increase above the normal range up to the $15^{\text {th }}$ post - operative day (Figure 1). Creatinine clearance increases to $72-78 \%$ of the preoperative creatinine clearance within several weeks postoperatively.

Table 5: Average creatinine levels before nephrectomy and on the $3^{\text {rd }}$ and $15^{\text {th }}$ post - operative

\begin{tabular}{|c|c|c|c|}
\hline Reference values & Before nephrectomy & $\mathbf{3}^{\text {rd }}$ day post-op & $\mathbf{1 5}^{\text {th }}$ day post-op \\
\hline $0.9-2.2 \mathrm{mg} / \mathrm{dl}$ & $1.27 \mathrm{mg} / \mathrm{dl}$ & $1.92 \mathrm{mg} / \mathrm{dl}$ & $2.5 \mathrm{mg} / \mathrm{dl}$ \\
\hline
\end{tabular}

Statistical analysis revealed a significant increase of creatinine level regardless of animal's age after unilateral nephrectomy on its $3^{\text {rd }}$ post - operative day up to 15 days post - surgery. No significant difference was seen between the two groups of experimental animals under study all of which have almost the same result.

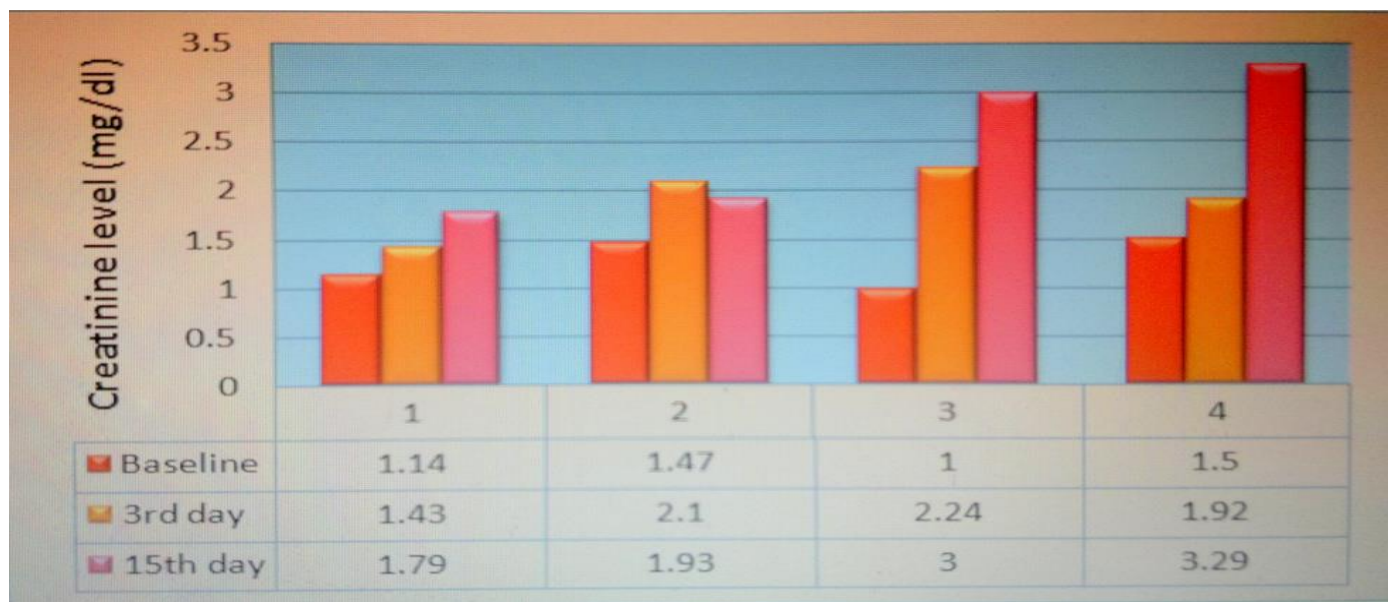

Figure 1: Graphical presentation of the Creatinine level before surgery and on the $3^{\text {rd }}$ and $15^{\text {th }}$ post - operative day. 
Table 6 shows the $3^{\text {rd }}$ and $15^{\text {th }}$ post - operative day of BUN (Blood Urea Nitrogen) level. Experimental animal number 2 showed slightly above normal BUN level on the $3^{\text {rd }}$ post - operative day, and the rest remained on its normal range. On its $15^{\text {th }}$ post - operative day experimental animal number 4 has a BUN of $34.41 \mathrm{mg} / \mathrm{dl}$ slightly above the normal value while the remaining three were within the normal range. BUN blood levels become higher when the kidneys are not capable of filtering them out of the system, due to injury or the onset of a disease (French et.al., 2012).

Table 6: Average values of BUN (Blood Urea Nitrogen) levels before nephrectomy and on the $3^{\text {rd }}$ and $15^{\text {th }}$ post - operative day

\begin{tabular}{|c|c|c|c|}
\hline Reference values & Before nephrectomy & $\mathbf{3}^{\text {rd }}$ day post-op & 15 $^{\text {th }}$ day post-op \\
\hline $19-34 \mathrm{mg} / \mathrm{dl}$ & $23.6 \mathrm{mg} / \mathrm{dl}$ & $31.14 \mathrm{mg} / \mathrm{dl}$ & $32.35 \mathrm{mg} / \mathrm{dl}$ \\
\hline
\end{tabular}

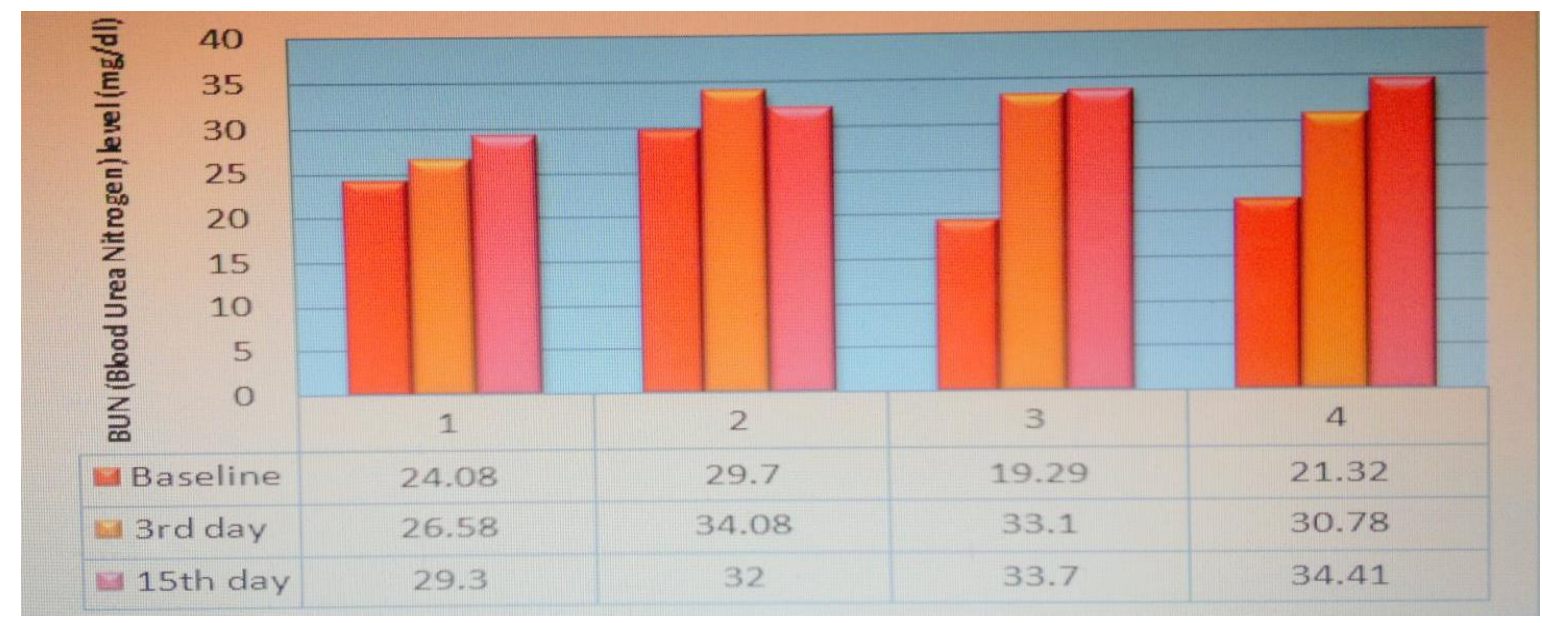

Figure 2: Graphical presentation of the BUN (Blood Urea Nitrogen) level before surgery and on the 3 rd and 15 th post - operative day.

Statistical analysis revealed a significant difference of BUN values of all experimental animals regardless of age before surgery and on its post - operative period ( $3^{\text {rd }}$ and $15^{\text {th }}$ day). No significant difference however was seen among the two age groups.

\section{Acknowledgment}

Heartfelt acknowledgment goes to Miss Krisna Mae Diaz, a senior clinician of the College of Veterinary Medicine, University of Eastern Philippines, who did the collection of feral cats \& assisted the author in the laboratory works for this particular experimental study.

\section{References}

[1] Birchard SJ, Sherding RJ (2000). Saunders Manual of Small Animal Practice 2nd edition. Pp. 938, 940.

[2] Chapman D, Moore R, Scott K, Branko B (2010). PMC2950769. Residual renal function after partial or radical nephrectomy for renal cell carcinoma. (http://www.ncbi.nlm.nih.gov/pmc/articles/PMC2950769/)

[3] Chew Dibartola (1998). Interpretation of Canine and Feline Urinalysis. P. 65

[4] Coles EH (1980). Veterinary Clinical Pathology 3rd edition. Pp. 219-220 
[5] De Caterina RM, Lanza M, Manca G, Strata GB, Maffei S and Salvatore L (2013). Bleeding time and bleeding: an analysis of the relationship of the bleeding time test with parameters of surgical bleeding. Republic Act No. 8485, otherwise known as the "Animal Welfare Act of 1998.

[6] Degner DA (2004). Kidney Tumors in Dogs and Cats (http://www.vetsurgerycentral.com/oncology_kidney_tumors.htm)

[7] Dyce, Sack, Wensing. Texbook of Veterinary Anatomy. Pp. 174-177

[8] Fieldorczyk DM (2011). Renal Failure in Cats. (http://www.misericordia.edu/honorus/dfpaper.cfm)

[9] Fleck C, Bräunlich H (1984) Exp Pathol; 25(1) :3-18. Journal Article Review. Kidney_function_after_unilateral_nephrectomy_

[10] French TW, Blue JT, Stokol T (2012). Routine Urinalysis/ (http://ahdc.vet.cornell.edu/clinpath/modules/ua- rout/ua-rout.htm) wikipedia.org/wiki/Cat

[11] Hines R (2012). Normal Feline \& Canine Blood Values Blood, Temperature, Urine and Other Values for Your Dog and Cat (http://www.2ndchance.info/normaldogandcatbloodvalues.htm)

[12] Khan CM (2010). The Merck Veterinary Manual 10th edition. Pp. 2822-2824, 2826

[13] Ruotsalo K, Tant M (2011) Urinalysis (http://www.vcahospitals.com/main/pet-health-information/article/animal-health/urinalysis/406)

[14] Schindler E (1982) Mar 4;100(9):383-4. [Article in German]. Fortschr Med. National Center for Biotechnology Information, U.S. National Library of Medicine 8600 Rockville Pike, Bethesda MD, 20894 USA.

[15] Sirois, Margi (1995). Mosby's Fundamentals of Veterinary Technology. Veterinary Clinical Laboratory Procedures. USA. 